\title{
Analisis Lokasi Penjualan Berbasis Data Geografis Menggunakan Perangkat Lunak Google Map API Studi Kasus PT. Johnson Home Hygiene Product
}

\author{
Erick Harlest Budi Raharjo \\ Fakultas Teknologi Informasi, Program Studi Teknologi Infomasi \\ Universitas Bina Sarana Informatika \\ erick.harlest@gmail.com
}

\begin{abstract}
Abstrak
Sistem Informasi Geografis sebagai sistem komputer yang digunakan untuk memanipulasi data spasial. Sistem ini dapat diimplementasikan dengan perangkat keras dan perangkat lunak yang berfungsi untuk akuisisi dan verifikasi data, kompilasi data, penyimpanan data, perubahan dan pembaruan manajemen data dan pertukaran data, manipulasi data, pemanggilan dan penyajian data serta analisis data. Definisi Sistem Informasi Geografis adalah dasar penelitian ini dalam menerapkan analisis berbasis geografis menggunakan perangkat lunak Google Map API. Sampel dipilih di dalam dan sekitar wilayah Cibubur dengan populasi yang terjangkau. Proses pengambilan data dari 2.755 toko dalam format gambar diambil menggunakan Garmin 550. Pemrosesan data ini menghasilkan pemetaan lokasi geografis yang divisualisasikan melalui koneksi Internet dan diunggah ke Google Map sehingga koordinat toko atau outlet dapat divisualisasikan dengan bantuan Browser Web. Dengan memvisualisasikan lokasi koordinat akan membantu manajemen dalam menganalisis penjualan berdasarkan data geografis.
\end{abstract}

\section{Kata kunci: Analisis Lokasi Penjualan, Data Geografis dan Google Map API}

\begin{abstract}
Geographic Information Systems as a computer system that is used to manipulate spatial data. This system is implementable with hardware and software that works for acquisition and verification of data, data compilation, data storage, changes and updates to data management and data exchange, data manipulation, calling and data presentation and analysis of data. Definition of Geographic Information Systems is the basis of this research in applying geographic-based analysis using the Google Map API software. Samples were selected in and around the area Cibubur, an affordable population. The data retrieval process of 2755 stores in image format was taken using a Garmin 550. The processing of this data produced geographic location mapping visualized through an Internet connection and uploaded to Google Maps so that the coordinates of the stores or outlets can be visualized with the help of a Web Browser. By visualizing the location of the coordinates will assist management in analyzing geographic data based on sales.
\end{abstract}

Keywords: Sales Location Analysis, Geographic Data, and Google Map API

\section{PENDAHULUAN}

Pesatnya perkembangan teknologi secara tidak langsung mendorong perusahaan berkembang untuk membuat sebuah terobosan analisis data yang dapat memudahkan dalam mengambil keputusan. PT. Johnson Home' Hygiene Product bergerak pada bidang Home Cleainig 
tepatnya pada industry rumah tangga yang menyediakan alat pembersih, penyejuk dan perawatan.

Dalam menjalankan bisnis PT. Johnson Home Hygiene Product membutuhkan metode analisis penjualan dan sangat diharapkan dapat membantu proses bisnis yang sedang berlangsung. Dengan memanfaatkan cepatnya kemajuan teknologi merupakan solusi cerdas dimana bisnis akan lebih berkembang, dan dapat bersaing dengan kompetitor.

Analisis berbasis geografis merupakan sebuah solusi dalam proses distribusi produk pada pasar tradisional.

\section{Rumusan Masalah}

Perumusan masalah penelitian ini yaitu "Bagaimana memvisualisasikan pemetaan area sales Cibubur sebagai pengembangan Sistem Informasi Geografis PT. Johnson Home Hygiene Product

\section{Tujuan Penelitian}

Tujuan dari penelitian ini adalah sebagai berikut:

1. Mengidentifikasi pelaksana di area atau wilayah yang menjadi target penjualan.

2. Memvisualisasikan secara akurat outlet yang telah menjadi target per sales di wilayah Cibubur.

3. Membantu pengambilan keputusan dalam membuat pembagian aren yang akan menjadi target penjualan selanjutnya.

\section{Manfaat Penelitian}

Memuat Manfaat dari Tujuan yang dicapai dari penelitian ini adalah sebagai berikut:
1. Pelaksana diwilayah area penjualan lebih mudah mengidentifikasi.

2. Mengvisualisasikan area outlet-outlet yang Telah dan Belum Menjadi target per sales di wilayah Cibubur.

3. Membantu pengambilan keputusan dalam membuat strategi bauran pemasaran.

\section{Tinjauan Pustaka}

Merujuk penelitian terdahulu dari penulis/peneliti sebelumnya diantaranya:

1. Sistem Informasi Geografis menggunakan ArcView GIS oleh Eko Budi Yanto, pengelolaan lingkungan dan dampak bencana alam dalam data $\operatorname{spasial}(2005)$

2. Sistem Informasi pemandu turis berbasis web Google Maps oleh Sudarman, Piarsa, Buana(2013).

3. Sistem Informasi Geografis berbagi Leptospirosis Epidemiologi oleh Lausuwan 2012 di thailand.

4. Sistem dukungan pengambilan keputusan pencarian pasar komersial oleh Piarsa, Sudana, Gunadi 2012 di India

5. Sistem informasi Geografis berbasis Web Opensource pemandu turis oleh Nair 2011 di Bhopal.

\section{LANDASAN TEORI}

Sistem Informasi Geografis atau Geographic Information System menurut para ahli:

Menurut Aronoff (1989, p.17) Sistem Informasi Geografis adalah sistem informasi yang berdasarkan pada kerja komputer yang memasukan, mengelola, memanipulasi dan menganalisa data serta memberi uraian. 
Menurut Bernhardsen (2002, p.20) Sistem Informasi Geografis sebagai sistem komputer yang digunakan untuk memanipulasi data geografi. Sistem ini diimplementasian dengan perangkat keras dan perangkat lunak yang berfungsi untuk akusisi dan verfikasi data, kompilasi data, penyimpanan data, perubahan dan pembaharuan data, manajemen dan pertukaran data, manipulasi data, pemanggilan dan presentasi data serta analisa data

Data dalam sistem informasi geografis dikelompokkan dalam dua bagian, yaitu data spasial dan data non spasial, ada pengertian dari dua point tersebut dari seorang ahli yang bernama Eko Budiyanto (2005,p.50) , adalah sebagai berikut :

1. Data spasial

Data spasial merupakan data yang penting dalam sistem informasi geografis. data spasial memiliki 2 konsep model, yaitu data vektor dan model data raster.

2. Data non Spasial

Data non spasial adalah data yang merepresentasikan aspek - aspek dimodelkannya. Data ini sering disebut juga data atribut. Dalam suatu peta, atribut biasaanya disajikan sebagai teks atau legenda.

3. Google Map API

Google Map untuk pertama kali perkenalkan oleh Google pada bulan Febuari tahun 2005 dikembangkan oleh Danish brother yaitu Lars dan Jens Rasmussen mendirikan 2 Technology sebagai solusi pemetaan, kemudian perusahaan ini diakuisisi oleh Google pada tahun 2004. Hingga saat ini google maps telah berevolusi dengan versi Google Maps API
(Aplication Programming Interface).

Menurut (Svennerberg

Gabriel:2010.p2).

\section{METODE PENELITIAN}

Adapun Jenis Penelitian ini terbagi menjadi:

1. Penelitian Data Spasial

Penelitian dengan model data vektor yang dinyatakan dalam bentuk titik koordinat toko yang menjadi objek dari penelitian dan lokasi yang akan di ketahui menggunakan Google Map Api.

2. Penelitian Non Spasial

Penelitian merepresentasikan aspek deskripsi dari fenomena yang akan dimodelkan mencakup item dan properti.

Pemilihan sampel dilakukan dengan meneggunakan Cluster Sampling (Area Sampling) yang merupakan turunan dari tehnik Probabilty Sampling melihat fakta dalam keadaan sebenarnya dengan melakukan pemotretan dengan menggunakan alat garmin serta toko-toko tersebut diberikan kode khusus dimana untuk menandakan titik koordinat dari toko didaerah yang menjadi pelanggan salesman, dan selanjutnya supervisor melakukan pengawasan.

Teknik sampling daerah ini sering digunakan melalui dua tahap yaitu tahap pertama menentukan sample daerah dan tahap berikutnya menentukan toko atau outlet yang ada pada daerah itu secara sampling juga. Teknik ini dapat digambarkan seperti gambar 2 berikut (Sugiyono, 2013,p.120). 


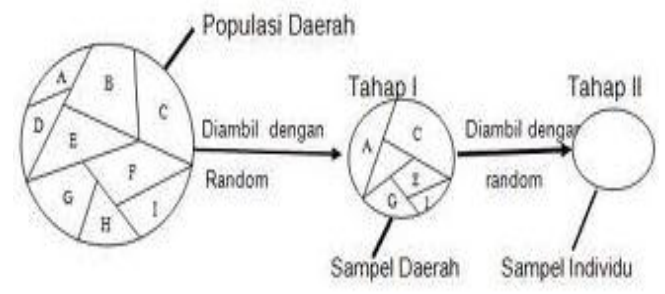

Gambar 1. Teknik Cluster Random Sampling

\section{Kerangka Berpikir/Alur Penelitian/Dsb}

Berikut adalah kerangka pemikiran dari penelitian :

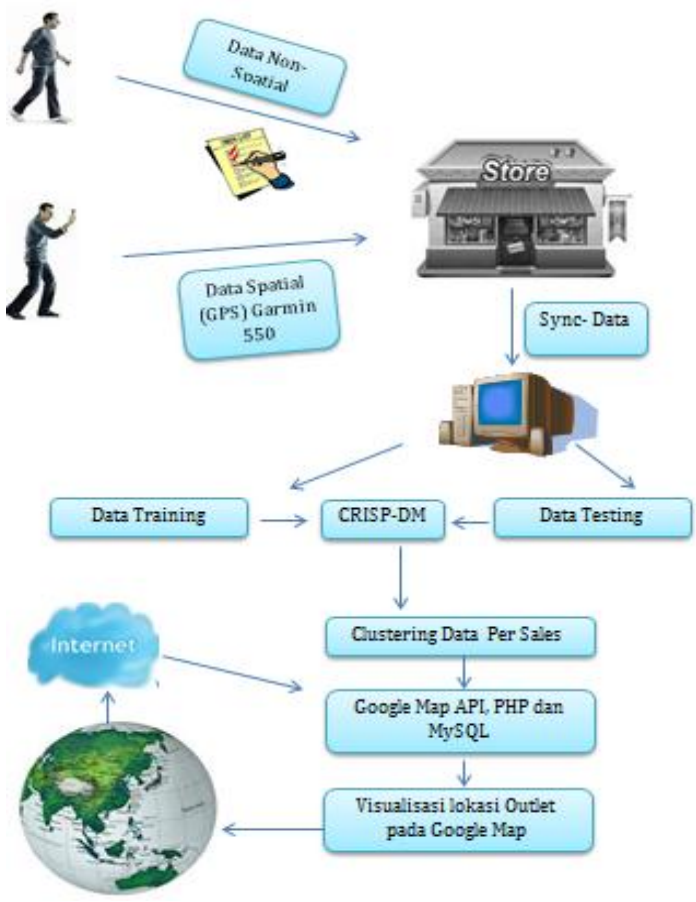

Gambar 2. Kerangka Pemikiran Pemecahan Masalah

Clusteing adalah proses klasifikasi satu set objek data ke dalam beberapa kelompok atau cluster memiliki kemiripan yang tinggi tetapi sangat berbeda dengan objek dalam cluster lain. Ketidak miripan dan persamaan dinilai berdasarkan nilai atribut yang menggambarkan objek dan sering melibatkan jarak pengukuran. Clustering sebagai alat data mining memiliki akar dibanyak area aplikasi seperti Biolog , Security, Business Intelijen dan Web Search. (Han and Kamber, 2006).

\section{ANALISIS DAN PERANCANGAN}

Rancangan tahapan analisa dan susunan konsep dan alur rancangan yang digunakan sebagai bahan dalam analisa dan perancangan system, sebagaimana pada Use Case Diagram Interkasi Tim Sales dengan Outlet yang menjadi target:

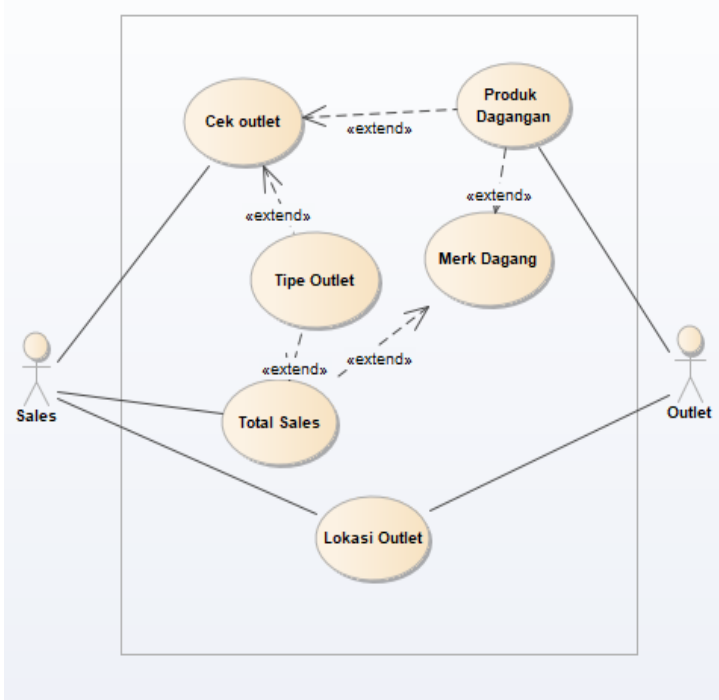

Gambar 3. Use Case Diagram

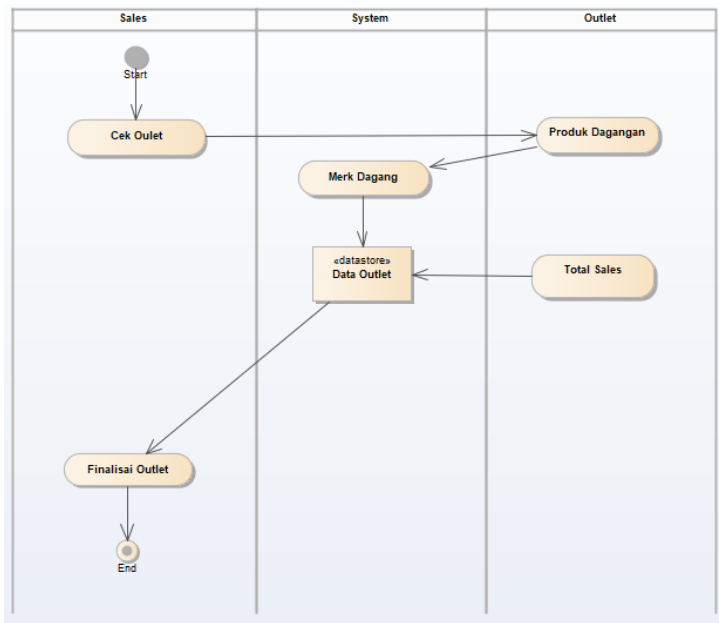

Gambar 4. Activity Diagram 


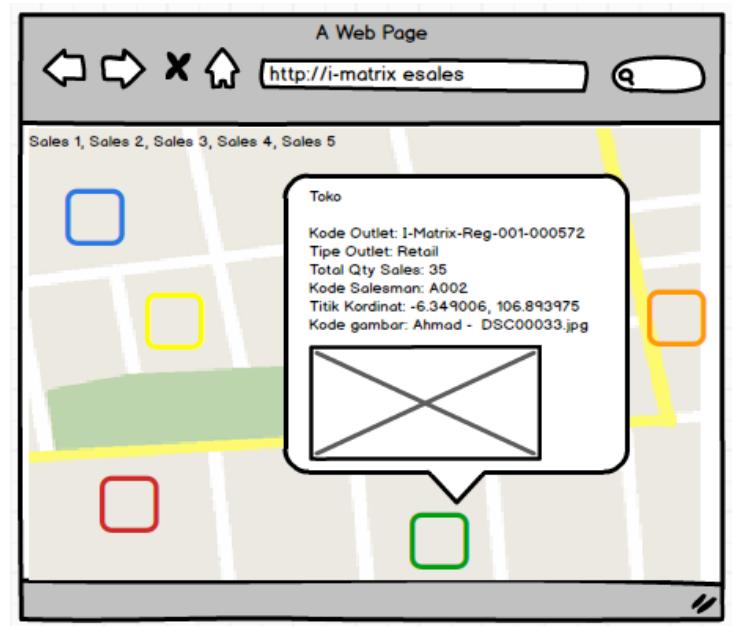

Gambar 5. Mokcup Interface Visualisasi

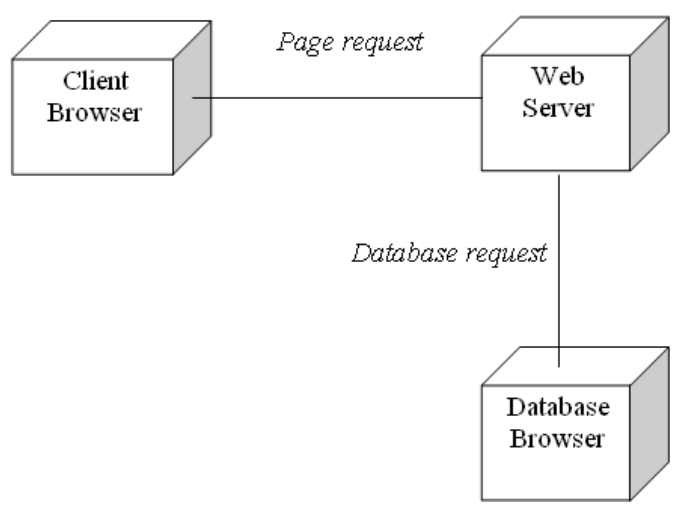

Gambar 6. Deployment Diagram

\section{IMPLEMENTASI DAN PEMBAHASAN}

Pemaparan hasil penelitian ini meliputi gambaran singkat wilayah cibubur dan sekitarnya, sebagai deskripsi data penelitian pada tiap variabel yang meliputi tabel distribusi. Cibubur secara geografis terletak pada 6o 20' 58' Selatan, 106 52' 37" Timur, sebuah desa atau kelurahan di daerah Kecamatan Ciracas, Jakarta Timur dengan total populasi 2755 outlet yang menjadi target diwilayah ini.

Setiap Toko Atau outlet yang Telah Bertransaksi Diberi Kode Sebagai Berikut:

spatial-001-000001

s/d MATRIX-001 002755

MATRIX-XXX XXXXXX
Garmin merupakan alat yang digunakan salesman sebagai media untuk mengambil gambar dari setiap outlet atau toko yang dikunjungi oleh salesman. Sedangkan proses untuk menyalakan Garmin 550 dilakukan dengan menekan bagain kanan Garmin 550 selama lebih kurang 2 detik dan proses mematikan dilakukan dengan menekan tombol yang sama dengan waktu penekanan tombol lebih kurang dari 2 detik. Secara keseluruhan visualisasi ini terdiri dari sebuah file HTML dengan Google Map yang dimuat, bentuk pencarian dan set data yang telah ditentukan, dan skrip JavaScript. Sisi klien HTML dan JavaScript file membuat permintaan ke server. Sisi server terdiri dari sebuah file PHP yang menjembatani kesenjangan antara Ajax dan menghubungkan ke database MySQL. Hasilnya dikembalikan sebagai respon XML untuk mesin Ajax.

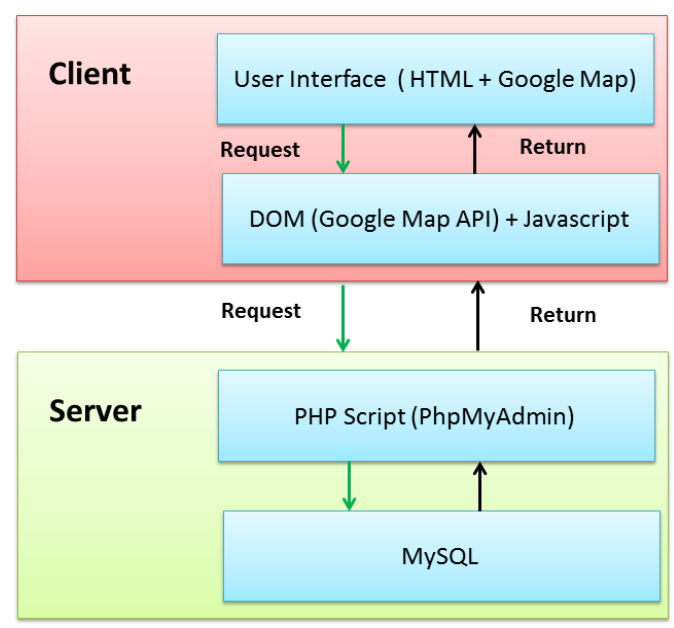

Gambar 7. Asitektur Diagram

Dengan memanfaatkan data training yang digunakan untuk menganalisis toko atau outlet yang terdapat diarea cibubur dan sekitar sehingga diperlukan beberapa tahapan proses yang menjadikan cluster dengan langkah-langkah sebagai berikut:

1. Inisialiasi 
2. Iterasi Sales Acep

3. Iterasi Sales Ahmad

4. Iterasi Sales Lukman

5. Iterasi Sales Maman

6. Iterasi Sales Nimin

7. Centroid,

Populasi area sales terbanyak yang dihasilkan adalah:

Tabel 1. Populasi Area Sales

\begin{tabular}{|c|c|c|c|c|}
\hline Sales & Area & lon & Lat & $\begin{array}{l}\text { Tot } \\
\text { al }\end{array}$ \\
\hline Acep & Cibubur & $\begin{array}{l}- \\
6.357355\end{array}$ & $\begin{array}{l}106.8801 \\
5\end{array}$ & 189 \\
\hline Ahmad & $\begin{array}{l}\text { B. } \\
\text { Ampar }\end{array}$ & $\begin{array}{l}- \\
6.276225\end{array}$ & $\begin{array}{l}106.8619 \\
4\end{array}$ & 198 \\
\hline Lukman & Tugu & $\begin{array}{l}- \\
6.371941\end{array}$ & $\begin{array}{l}106.8523 \\
14\end{array}$ & 130 \\
\hline Maman & Munjul & -6.35198 & $\begin{array}{l}106.8959 \\
16\end{array}$ & 114 \\
\hline Nimin & Pekayon & $\begin{array}{l}- \\
6.347459\end{array}$ & $\begin{array}{l}106.8618 \\
54\end{array}$ & 169 \\
\hline \multicolumn{4}{|c|}{ Total Sales } & 800 \\
\hline
\end{tabular}

Wilayah penjualan dilakukan lima salesman , terlihat bahwa masih terdapat lintas wilayah penjualan, yang seharus hal ini tidak terjadi, dengan divisualisasikan proses penyebaran sales man masih perlu dilakukan lokalisasi untuk menjaga agar produk tetap diterima dimasyarakat dan memberikan kualitas yang baik serta ramah lingkungan Setelah data yang sudah diperolah dimasukan ke dalam tabel toutlet, selanjutnya ada menampilkan dengan Google Map Api dengan syntax script sebagai berikut:

<script src=

"https://maps.googleapis.com/maps/api/js? $\mathrm{v}=3 . \exp \&$ sensor $=$ false" $>\langle/$ script $>$

Pada function initialize () diletakan var myLatlng = new google.maps.LatLng(7.006401, 110.359572); agar yang di tampilkan adalah wilayah Pulau Jawa, dengan ukuran zoom yaitu 7, map-canvas disisipkan kedalam body html sehingga peta pulau Jawa dapat ditampilkan. Selanjutnya adalah menghubungkan database yang telah dibuat dengan menampilkan data pada tabel outlet.

Titik koordinat yang telah diperoleh melalui tabel toutlet kemudian dipetakan pada Google Maps untuk ditampilkan data toko atau outlet yang bertransaksi dengan salesman, pada browser menggunakan script yang menandakan iduser atau salesman sebagai berikut :

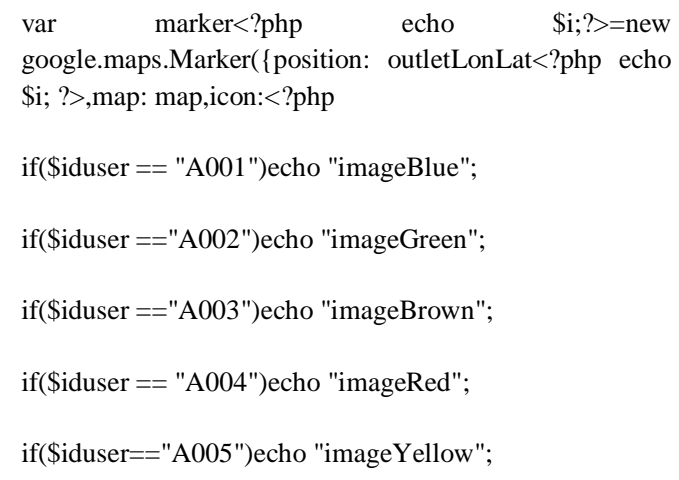

Sehingga dapat ditampilkan data yang dikelola dan dipetakan sesuai dengan titik koordinat yang telah diambil oleh salesman pada saat berkunjung ke toko atau outlet yang telah bertransaksi sebagai berikut:

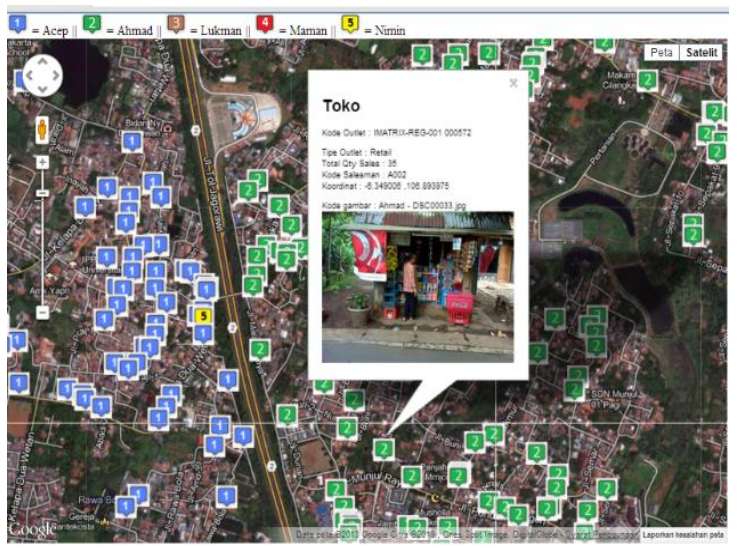

Gambar 8. Google Map I-Matrix

\section{KESIMPULAN}

Hasil dari Implementasi dan pembahasan dapat disimpulkan hasil tersebut dalam uraian sebagai berikut: 
1. Visualisasi outlet menunjukan masih terdapat salesman yang melintasi wilayah salesman lain penentuan batas wilayah menjadi faktor penting dalam proses distribusi.

2. Distribusi produk masih harus ditingkatkan untuk menjaga pasar dari persaingan dengan kompetitor.

3. Visualisasi outlet dengan Gooogle Map dipadukan dengan strategi pemasaran dengan menerapkan 4P.

\section{Saran}

Dari kesimpulan implementasi sistem informasi geografis dapat disarankan, sebagai berikut:

1. Harapan kedepan terus dikembangkan sehingga dapat memantau distribusi produk dan outlet retail.

2. Perlu adanya pengembangan berbasis aplikasi smartphone.

\section{DAFTAR PUSTAKA}

Aronoff, Stan (1989). Geographic Information Systems. A Management Perspective, Ottawa: WDL Publications

Burrough, P. A. (1986). Principles of Geographical Information Systems for Land Resource Assessment, Oxford University Press, Oxford.

Bernhardsen, T. (2002) Geographic Information Systems, in The Global Environment: Science, Technology and Management (eds D. Brune, D. V. Chapman, M. D. Gwynne, and J. M. Pacyna), Wiley-VCH Verlag $\mathrm{GmbH}$, Weinheim, Germany.

Harmon and Anderson (2003). The Design and implementation of Geographic Information Systems Wiley

Budiyanto, Eko. (2005). Sistem Informasi Geografis Menggunakan ArcView GIS. Yogyakarta: Andi
Han and Kamber, (2006), Data Mining: Concept and Techniques, 2nd ed

Sugiyono. (2013). Metode Penelitian Bisnis. Bandung. Alfabeta

Murai, S. (2008). JICA Net Distance Education on Remote Sensing and GIS for Developing Countries. International Archives of the Photogrammetry, Remote Sensing and Spatial Information Sciences, XXXVII, 191-195.

Sudarman, Piarsa, Buana (2013, January). Design and Implementation of Geographic Information System on Tourism Guide Using Web-Based Google Maps.Vol 10 No. 2. http://ijcsi.org/papers/IJCSI-10-1-2478-483.pdf (Akses 30 April 2013)

Lausuwan, (2012, July) Online web SISTEM INFORMASI GEOGRAFIS based services for spatial data and sharing of leptospirosis epidemiology information: Development of pilot project in mahasarakham province Thailand. Vol3:1. http://www.ipublishing.co.in/jggsvol 1no12010/volthree/EIJGGS3111.pdf

Piarsa, Sudana, Gunadi (2012, July) Webbased GIS by using Spatial Decision Support System (SDSS) Concept for Searching Commercial Marketplace Using Google MAP API. Vol. 50 No.7.http://research.ijcaonline.org/v olume50/number7/pxc3880867.pdf (Akses 30 April 2013)

Nair. (2011, February) Web Enable Open Source GIS-Based Tourist Information System For Bhopal City. Vol:No.2.http://www.ijest.info/docs/ IJEST11-03-02-001.pdf (Akses 30 April 2013)

Larose, Daniel T. (2005). Discovery knowledge in data. John Wiley's and Son

XAMPP,(2013).http://en.wikipedia.org/wi ki/XAMPP (Akses 30 Agustus 2013) Apache: (2013), https://httpd.apache.org/ (Akses 30 Agustus 2013) 
MySQL:(2013),http://en.wikipedia.org/wi ki/MySQL (Akses 30 Agustus 2013)

PHP (2013): http://www.php.net/ (Akses 30 Agustus 2013)

PhpMyAdmin,(2013),http://www.phpmya dmin.net/home_page/index.php (Akses 30 Agustus 2013)

Simple Maps,

https://developers.google.com/maps/ documentation/javascript/examples/ (Akses 30 Agustus 2013)

Simple Maps, (2013) https://developers.google.com/maps/ documentation/javascript/examples/ map-simple (Akses 30 Agustus 2013) 